\title{
The ISA Lab workshop: a Project based learning iniciative
}

\section{Orozco-Messana, Javier ${ }^{\text {a }}$, De la Poza, Elena ${ }^{\text {b }}$}

${ }^{a}$ Department of Mechanical Engineering and Materials, Universitat Politècnica de València, Spain, ${ }^{\mathrm{b}}$ Center of Economic Engineering, Universitat Politècnica de València, Spain

\begin{abstract}
In the context of higher education in the XXI century, the different stakeholders (markets, firms, households, States) assume prospective University graduates will be responsible for providing solutions to the most challenging societal problems, delivering sustainable projects and contributing to improve the quality of life of citizenship controlling for the local but also global impact. Academic staff adapt their role continuously to foster students into the acquisition of competences and skills to better fulfill the societal demands.

This paper deals with the process of conceptualization, design and implementation of a PBL workshop in an international and multidisciplinary environment. The ISA lab workshop was envisioned by an academic who ideated, planned, designed and empowered others into action. The result was the first edition of the ISA lab workshop, an international multidisciplinary workshop on sustainability.
\end{abstract}

Keywords: project based learning; higher education; sustainability; stakeholder. 


\section{Introduction}

Project-Based Learning (PBL) is an innovative approach to learning that teaches a multitude of strategies critical for success in the twenty-first century (Bell, 2010). This method uses problems as a starting point for the acquisition and integration of new knowledge (Barrows, 1986). Following García (2016), the PBS methodology embeds four main elements: (1) authenticity since the problems to solve are real; (2) research: students need to build their knowledge by discussing and gathering information; (3) use of techniques to plan, design, coordinate, control and deliver the project; (4) autonomy: students risk by making choices, assuming responsibility.

Students drive their own learning through inquiry, as well as work collaboratively to research and create projects that reflect their knowledge, (Bell, 2010). As a result, students develop general but also subject competencies by applying complicated processes and procedures such as planning, communication, research and self-directed learning, (Lasauskiene and Rauduvaite, 2015).

The implementation of the PBS as an education paradigm rather than a mere teaching learning method employed by one lecturer in a single course might require to introduce solutions at institutional level, to design a PBS model from its conception to its implementation, (Lasauskiene and Rauduvaite, 2015). Moreover, PBL can become the perfect tool for integrating multiculturalism and cross-disciplinary context by higher learning partner institutions cooperate in the design and implementation of educational programs based on PBL, (Arroyo-Cañada et al., 2016).

Thus, PBL is an overall approach to the design of learning environments; in their work Krajcik and Blumenfeld (2005) identify the principles of PBL and their lessons learnt about this methodology over ten years of experience providing a model for applying projectbased methods to classrooms across the curriculum.

This paper deals with the process of conceptualization, design and implementation of a PBL workshop in an international and multidisciplinary environment. The ISA lab workshop was envisioned by an academic who ideated, planned, designed and empowered others into action. The result was the first edition of the ISA lab workshop, an international multidisciplinary workshop on sustainability.

In the context of higher education in the XXI century, the different stakeholders (markets, firms, households, States) assume prospective University graduates will be responsible for providing solutions to the most challenging societal problems, delivering sustainable projects and contributing to improve the quality of life of citizenship controlling for the local but also global impact (Lehmann et al., 2008). Academic staff adapt their role continuously to foster students into the acquisition of competences and skills to better fulfill 
the societal demands. Harden and Crosby (2000), synthetized the academic staff roles, as a planer, facilitator, information provider, resource developer and a role model.

\section{ISA lab workshop: the Interdisciplinary Sustainability Assessment Laboratory}

The ISA lab workshop in its first edition was performed by academic staff from six institutions belonging to the Polimundus network - a collection of Universities seeking to promote Engineering Excellence in Research. The academic staff from the North American and European Universities of British Columbia (UBC), Cork (UCC), Cambridge (U.Cambridge), Delft (TU Delft) and Politècnica de Valencia (UPV) gathered for a week in the UPV campus located at Valencia, Spain, to conduct an experiment in a multinationaland interdisciplinary project-based learning workshop on sustainability.

The main goal of this workshop consisted of bringing academic staff from a myriad of areas of expertise (Engineering for Sustainable Development, Chemical Engineering, Energy, Built Environment, Architecture, Green Infrastructure, Law) and institutions but also students with diverse backgrounds, interests and cultures. They work on real sustainabilityoriented challenges and to explore the benefits of working in such an environment and to begin to shape a vision for the future needs in this area.

The novelty of this workshop relies on the heterogeneity of the drivers combined: the diversity of the academic body (the facilitators of the student's learning process), the independent background and origins of students, the PBL as the teaching approach employed, all rolled up by the enhance of promoting the sustainability in the region of Valencia.

Since courses at higher education Degrees are mostly organized in strict disciplinary environments, without providing the opportunity to cross with other disciplines, initiatives such as the ISA lab in Valencia can provide a safe space for staff and students to experiment with these methods, to learn from each other and reflect on the skills and approaches which might help them be more effective in the future.

\subsection{Design of the ISA lab workshop}

The dreamer and creator of the ISA lab was a UPV lecturer who recruited the crew of academics into the ISA lab workshop at its inception. Note, not all the lecturers knew each other in advance and the ISA lab design and implementation was their way of meeting.

Then, lecturers chose at least 2 students from their Universities of origin (at Master and undergraduate level). The only criterion established for the selection of students was their engagement in sustainability. Thus, a lecturer and at least two students represented each 
University involved in the workshop. During the ISA lab planning stage the communication between partners was through e-mail but also through visits from the UPV leader to the rest of institutions.

Once the main stakeholders involved in the workshop were confirmed, the stage of design started. The primary goal of learning by projects, required the identification of cases of study that covered the glocal condition: (i) to provide a real scenario in which a local problem in the region of the Valencian Community that requires action but (ii) in which the solutions could come from a global multidiscipinary perspective. It is relevant to comment that with the exception of the UPV academic staff, the rest of academic participants were not engaged with the projects previous to the ISA lab.

During the workshop the students would be provided with a portfolio of information for each of the cases of study selected. Then, they would tackle the six dimensions of each project (environmental, social, economic and technical) by analizyng the impact of the solutions presented. (Table 1 describes each project and the solutions presented to students for their analysis). 
Table 1. Description of the projects.

\begin{tabular}{|c|c|}
\hline Project & Place, description and solutions to analyze by each team \\
\hline $\begin{array}{l}\text { NZEB* } \\
\text { refurbishment } \\
\text { in a natural } \\
\text { park }\end{array}$ & $\begin{array}{l}\text { Place: Font Roja (Alcoi), the city of Alcoi is nestled between two } \\
\text { natural parks. } \\
\text { Description: The city council decided to refurbish a group of houses } \\
\text { at the core of the Font Roja natural Park as the basis for a } \\
\text { sustainability program for the city. } \\
\text { Solutions to analyze: The project aims at the refurbishment of these } \\
\text { houses which will demonstrate the feasibility of a sustainable built } \\
\text { environment where different academic, innovation and social } \\
\text { activities will be carried out. The rural activities and sustainable } \\
\text { tourism are seen as a huge opportunity to boost the importance of } \\
\text { Alcoi in this context. }\end{array}$ \\
\hline $\begin{array}{l}\text { NBSs** for } \\
\text { the Benicalap } \\
\text { neighbourhood }\end{array}$ & $\begin{array}{l}\text { Place: Tabarca island (Alicante). } \\
\text { Description: An old lighthouse will be refurbished under nZEB } \\
\text { principles. } \\
\text { Solutions to analyze: The project focuses on refurbishing and } \\
\text { locating an innovation center for academic and demonstration } \\
\text { activities related to Sustainability through circular economy at the } \\
\text { lighhouse. the perspective of a sustainability multi- stakeholder } \\
\text { assessment. }\end{array}$ \\
\hline & $\begin{array}{l}\text { Place: Benicalap neighbourhood, (Valencia city) } \\
\text { Description: In Valencia city the green infrastructure concept has } \\
\text { been extended, to include new spaces such as "Casino del } \\
\text { Americano" and "Alqueria de la Torre" that allow to capitalize the } \\
\text { natural resources and promote population's well-being. } \\
\text { Solution to analyze: The project will propose a rehabilitation of the } \\
\text { traditional gardens of the buildings, including solutions such as: } \\
\text { vertical ecosystems for the decentralized treatment of gray water } \\
\text { integrated into buildings; bioclimatic strategies using the garden } \\
\text { components to comply with standards NZEB activities engaging the } \\
\text { citizenship related to urban orchards. }\end{array}$ \\
\hline
\end{tabular}

*Nearly zero enery buildings; **Naure based solutions

Source: Own performance 


\subsection{Implementation of the ISA lab workshop}

The ISA lab workshop spinned around the students learning. As a PBL workshop students were goal-oriented to solve real problems in the Valencia region. However, the ISA lab was an experiement in the sense that the design and implementation of the workshop was concurrent. Thus, there were no pre-planned solutions or correct answers, just an outline brief and a search for sustainable solutions.

The students worked in small groups over 5 days to deliver new concepts for these existing challenges, making the most of their talents as individuals and drawing on their respective disciplinary background.

Each morning a faculty staff delivered a keynote based on their expertise exercising a role of information and theme topic. The keynotes covered a wide range of topics, all related to sustainability.

Then, the students were grouped by the academic staff in teams of 3-4. Each team was combining different students institutions and backgrounds in order to foster multiculturalism, interdisciplinarism. Each group was assigned a project. They were asked to provide solutions based on sustainability but without forgetting economic, social and cultural dimensions. In order to propolse the cohesion of the teams, a social programme was also planned, where students and Faculty could meet and get to know each other as individuals.

At the end of the week students had to present their findings to the all group. A board composed of the academic staff would provide feedback, comments, suggestions and questions to their solutions. The participants received a certificate of participation at theworkshop but more important they met with peers but also with public and private institutions.

\subsection{Assessment of the ISA lab workshop}

Once the workshop concluded, students were reached by email and they were requested to provide feedback about the ISA lab workshop. They were asked the following 3 nonstructured questions:

1. Can you identify any aspects of the workshop or its delivery that you found particularly useful?

2. Do you have any suggestions as to how the workshop or its delivery might be improved?

3. Do you have any other relevant comments to make on the workshop or on your learning experience around it? 
All students (10 participants) emailed back their opinions about the workshop. About question 1, there was a complete consensus about the utility of the workshop. All participants agred on the positive aspect of working on multidisciplinary teams. They also highlighted the social program helped them to team up and unify their efforts on the project. On the other hand, about question 2 participants provided different suggestions, mainly about how they would have appreciated to have more information about the projects beforehand to the training in Valencia. In addition, the project scope might need some reshaped and guidelines about how to find solutions should be provided. Finally the common answer to question number 3 was the gratitude shown by participants for how their knowlwdge had improved from an academic and professional point of view by participating in the worksop.

\section{Conclusions}

This work deals with the process of definition, conceptualization and implementation of a multidisciplinary international project based learning workshop. The success of the ISA lab workshop was achieved in terms of satisfaction coming from the participants (lecturers and students) to the workshop but also from the different stakeholders proposing the projects who valued positively the outcomes of the workshop and the competences adquired by the students throughout the workshop.

The succes of the first edition of the ISA lab workshop will bring a new edition in 2018 . The second edition of the ISA lab workshop will embrace the former parties but also new international Universities and projects ideated by public and private bodies. In addition, at the host University, UPV, the ISA lab workshop brings together lecturers from different disciplines working together in the continuous process of improvement of higher education.

\section{References}

Arroyo-Cañada, F.J., Argila-Irurita, A.M., Solé-Moro, M.L. (2016). Competency-based Learning in a Real and Multicultural Marketing Consultancy Project, Procedia - Social and Behavioral Sciences, 228, 449-456.

Barrows, H.S. (1986). A Taxonomy of problem-based learning methods. Medical Education, 20 (6), 481-486.

Bell, S. (2010). Project-Based Learning for the 21st Century: Skills for the Future. The Clearing House: A Journal of Educational Strategies, Issues and Ideas, 83 (2), 39-43.

García, C. (2016). Project-based Learning in Virtual Groups - Collaboration and Learning Outcomes in a Virtual Training Course for Teachers. Procedia - Social and Behavioral Sciences, 228,100-105. 
Harden, R. M. \& Crosby, J. R. (2000). The good teacher is more than a lecturer: the twelve roles of the teacher. Medical Teacher, 22, 334-347.

Krajcik, J., \& Blumenfeld, P. (2005). Project-Based Learning. In R. Sawyer (Ed.), The Cambridge Handbook of the Learning Sciences (Cambridge Handbooks in Psychology, pp. 317-334). Cambridge: Cambridge University Press.

Lasauskiene, J. \& Rauduvaite, A. (2015). Project-Based Learning at University: Teaching Experiences of Lecturers, Procedia - Social and Behavioral Sciences, 197, 788-792.

Lehmann, M., Christensen, P., Du, X., Thrane, M. (2008) Problem-oriented and projectbased learning (POPBL) as an innovative learning strategy for sustainable development in engineering education. European Journal of Engineering Education, 33(3), 283-295. 